\title{
Crystal chemistry and electronic structure of the metallic lithium ion conductor, LiNiN
}

Zlatka Stoeva, ${ }^{a}$ Bernd Jäger, ${ }^{b}$ Ruben Gomez, ${ }^{a}$ Sabri Messaoudi, ${ }^{c}$ Mouna Ben Yahia, ${ }^{c}$ Xavier Rocquefelte, ${ }^{c}$ Gary B. Hix, ${ }^{d}$ Walter Wolf, ${ }^{e}$ Jeremy J. Titman, ${ }^{a}$ Régis Gautier, ${ }^{c}$ Peter Herzig ${ }^{b}$ and Duncan H. Gregory..$^{*}$

${ }^{\text {a }}$ School of Chemistry, University of Nottingham, University Park, Nottingham, NG7 2RD, UK.

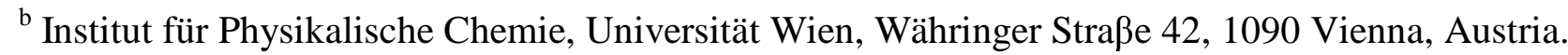

${ }^{\mathrm{c}}$ Laboratoire de Chimie du Solide et Inorganique Moléculaire, UMR 6511, CNRS - ENSC Rennes, Institut de Chimie de Rennes, Campus de Beaulieu, 35700 Rennes, France.

${ }^{\mathrm{d}}$ School of Biomedical and Natural Science, Nottingham Trent University, Clifton Lane, Nottingham, NG11 8NS, UK.

${ }^{\mathrm{e}}$ Materials Design s.a.r.l., 44 Avenue F-A. Bartholdi, 72000 Le Mans, France.

${ }^{\mathrm{f}}$ WestCHEM, Department of Chemistry, Joseph Black Building, University of Glasgow, Glasgow G12 8QQ, UK.

Author E-mail: D.Gregory@ chem.gla.ac.uk

\section{Supporting Information}




\section{Simulation of ${ }^{7} \mathrm{Li}$ MAS-NMR spectrum for LiNiN.}

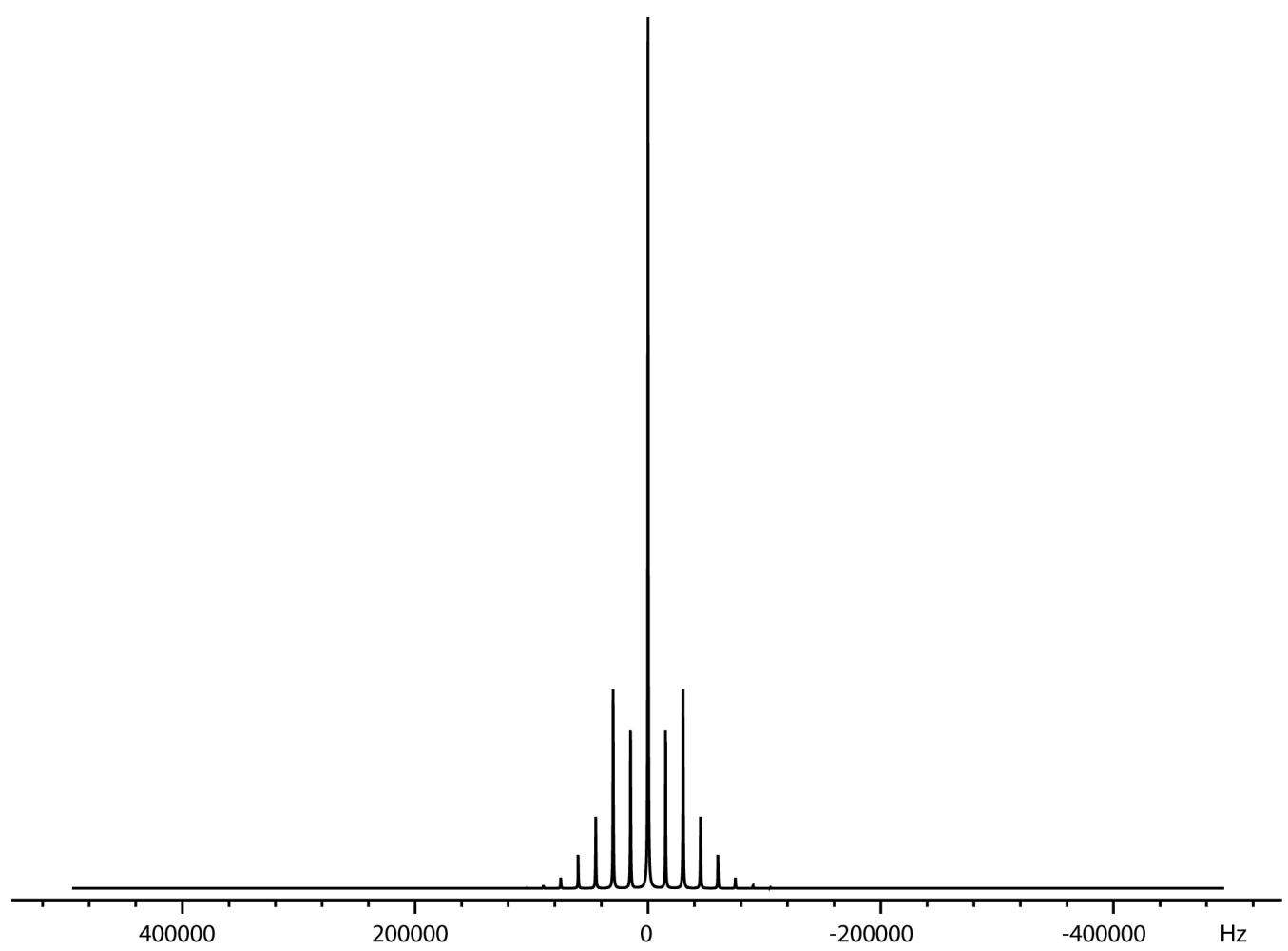

Figure S1. Simulation of CQ $=145 \mathrm{kHz}$ lithium-7 MAS spectrum with MAS rate $15 \mathrm{kHz}$ and Larmor frequency $116 \mathrm{MHz}$. 